\title{
Biodegradation of Phenol by Unacclimated and Phenol-acclimated Activated Sludge: Effects of Operational Factors on Biodegradation Efficiency and Kinetics
}

\author{
Sam Suat Peng and Ng Si Ling* \\ School of Chemical Sciences, Universiti Sains Malaysia, \\ 11800 USM Pulau Pinang, Malaysia \\ *Corresponding author: slng@usm.my
}

Published online: 15 November 2017

To cite this article: Sam, S. P. \& Ng, S. L. (2017). Biodegradation of phenol by unacclimated and phenol-acclimated activated sludge: Effects of operational factors on biodegradation efficiency and kinetics. J. Phys. Sci., 28(3), 53-67, https://doi.org/10.21315/jps2017.28.3.4

To link to this article: https://doi.org/10.21315/jps2017.28.3.4

\begin{abstract}
This study was conducted to investigate the effects of operational factors, namely: 1. type of activated sludge; 2. activated sludge concentration; 3. initial phenol concentration; and 4. addition of sucrose; on the biodegradation of phenol in batch experiments. At various initial phenol concentrations, complete phenol biodegradations with chemical oxygen demand (COD) removal of $95 \%$ were achieved by both unacclimated and phenol-acclimated activated sludge. The performance of biodegradation was greatly enhanced, with biodegradation time shortened from 330-1260 to 35-330 min for initial phenol concentrations of 25-250 $\mathrm{mg} \mathrm{l}^{-1}$, when the activated sludge was acclimated to the target compound, despite the low acclimation concentration of $50 \mathrm{mg} \mathrm{l}^{-1}$. Phenol biodegradation time was found to decrease with increasing activated sludge concentration and decreasing initial phenol concentration. In the presence of sucrose as co-substrate, biodegradations of phenol by both unacclimated and phenol-acclimated activated sludge were improved. The kinetic data for the biodegradation of phenol was well-fitted into pseudo-first-order model. The values of rate constant of phenol-acclimated activated sludge were found to be higher compared to those of unacclimated activated sludge under all the operational conditions studied. For phenol-acclimated activated sludge, the values of pseudo-first-order rate constant, $k$, were observed to decrease with increasing concentration of activated sludge and decreasing initial phenol concentration.
\end{abstract}

Keywords: Biodegradation, operational factors, phenol, acclimation, kinetics 


\section{INTRODUCTION}

Phenolic compounds are widely used in the industrial fields such as oil refining, petrochemical, pharmaceuticals, phenol manufacturing, agro-industry, coke and coal gasification industries. ${ }^{1-4}$ These compounds are carcinogenic and dangerous due to their toxicity and high bioaccumulation rate along the food chain. ${ }^{3}$ Therefore, phenolic-containing effluents have to be treated properly before discharged into discharge into external environment. According to the Environmental Quality Act 1974, the discharge of industrial effluent containing phenol is limited to 0.001 and $1.0 \mathrm{mg}^{-1}$ for Standard A and B, respectively.

Increasing environmental awareness coupled with more stringent regulation standards have triggered various industries to challenge themselves in seeking appropriate wastewater treatment technologies. ${ }^{5}$ The removal of phenolic compounds from wastewater can be achieved using physical, chemical or biological methods. However, physico-chemical methods such as activated carbon adsorption, reverse osmosis, solvent extraction, electrolytic oxidation and chemical oxidation are costly and show incomplete removal of toxic pollutants., ${ }^{2,-7}$ In contrast, biological approaches provide economical and eco-friendly treatments of phenolic compounds in addition to the low possibility of by-product formation and hence mineralisation of phenols is achievable. ${ }^{8}$ Activated sludge process is one of the widely used biological treatment systems in which the wastewater is treated with a mixture of microorganism. ${ }^{9}$ In comparison with the pure culture, complete mineralisation of phenolic compounds using mixed culture is more practical and efficient. ${ }^{1,10}$

Sequencing batch reactor (SBR) system, one of the activated sludge processes, provides a good alternative compared to others due to its effectiveness and operational flexibility. Studies have shown the complete mineralisation of various phenolic compounds using activated sludge obtained from sequencing batch reactor systems. ${ }^{10-13}$ Nonetheless, it was observed that the biodegradation of phenolic compounds was mostly conducted using activated sludge that was acclimated to the target compound beforehand., ${ }^{2,10,13,14}$ Acclimated activated sludge consists of microorganisms with adjusted morphological, behavioural, physical or biochemical traits in response to changes in the environment. A study has presented that complete removal of $4 \mathrm{CP}$ up to $300 \mathrm{mg}^{-1}$ was achieved by employing acclimated activated sludge. ${ }^{10}$ In the study by Vazquez-Rodriguez et al., no lag phase was found during the biodegradation of phenol by activated sludge acclimated to $700 \mathrm{mg} \mathrm{l}^{-1}$ of phenol. ${ }^{13}$ Similar result was reported by Janeczko and Oleszkiewicz that immediate biodegradation of 2-nitrophenol (2NP) without any lag was shown using acclimated activated sludge, whereas a 170 to $230 \mathrm{~h} \mathrm{lag}$ 
was observed before the initiation of 2NP removal using unacclimated activated sludge..$^{14}$ In view of the wide range concentration of phenol in industrial wastewater, Lim et al. investigated the response of the low-strength phenol-acclimated sludge to shock loading of high phenol concentration and found that activated sludge acclimated to $140 \mathrm{mg} \mathrm{l}^{-1}$ was able to achieve complete degradation of phenol up to $1050 \mathrm{mg} \mathrm{l}^{-1}{ }^{1}$. However, to the best of our knowledge, studies on the effect of operational factors on the phenol biodegradation efficiency and kinetics using unacclimated and low-strength acclimated activated sludge are still limited.

Cometabolism is defined as biotransformation of non-growth substrates by organism that require alternative substrate for energy or cell growth. ${ }^{15,16}$ Studies had been carried out in adding different types of co-substrate aiming to improve the removal efficiency of phenol. Enhancement of inhibition tolerance of pure culture, P. putida towards phenol was observed by Lob and Tar when the system was supplemented with optimum concentrations of yeast extract and glucose, respectively. ${ }^{6}$ On the other hand, adverse effect of co-substrate was reported by V. Arutchelvan et al. in which the phenol degradation efficiency was found to reduce comparatively in the presence of dextrose as co-substrate. ${ }^{17}$ In this study, the feasibility of using sucrose as the co-substrate to improve the biodegradation of phenol was investigated.

In the light of the above observations, the main objective of this study is to evaluate the effects of operational factors, namely: 1 . type of activated sludge; 2 . concentration of activated sludge; 3 . initial concentration of phenol; and 4. addition of sucrose; on the removal efficiency of phenol. Additionally, the biodegradation kinetics of phenol was also assessed under different operational conditions.

\section{EXPERIMENTAL}

\subsection{Culturing and Acclimation of Activated Sludge}

The seed of activated sludge was collected from a local municipal sewage treatment plant at Batu Ferringhi, Penang, Malaysia. It was then cultured using two identical laboratory-scale SBRs, namely, R-P and R-C. Each reactor with the working volume of 51 was operated with five operational periods of FILL, REACT, SETTLE, DRAW and IDLE with the ratio of time of 2: 8: 1: 0.75: 0.25 for a cycle of $24 \mathrm{~h}$. The reactors were fed with the base mix of the following composition (in mg l-1): bacto-peptone (188), sucrose (563), $\mathrm{KH}_{2} \mathrm{PO}_{4}$ (32), $\mathrm{K}_{2} \mathrm{HPO}_{4}(180)$, $\left(\mathrm{NH}_{4}\right)_{2} \mathrm{SO}_{4}(212), \mathrm{NaHCO}_{3}(500), \mathrm{MgSO}_{4}(49), \mathrm{FeCl}_{3} \cdot \mathrm{H}_{2} \mathrm{O}$ (18.8) and $\mathrm{CaCl}_{2}$ (40). A volume of 3.51 of feed solution was added into the reactor and equal volume of treated effluent was withdrawn from the reactor during the FILL and DRAW 
periods, respectively, for each cycle. The low-strength phenol-acclimated activated sludge was cultured in reactor R-P, in which the activated sludge was gradually acclimated to phenol by increasing the phenol concentration from 5 to $50 \mathrm{mg} \mathrm{l}^{-1}$ with both sucrose and bacto-peptone concentrations gradually reduced to half. The reactor R-C served as control without acclimation. Once the quasi-steady state was attained as indicated by fairly constant concentrations of mixed liquor suspended solids (MLSS) of $4500 \pm 300 \mathrm{mg} \mathrm{l}^{-1}$ and $3500 \pm 300 \mathrm{mg} \mathrm{l}^{-1}$ for reactors R-C and $\mathrm{R}-\mathrm{P}$, respectively, the unacclimated and phenol-acclimated activated sludge were used in the biodegradation studies.

\subsection{Batch Biodegradation Studies}

The studies of biodegradation of phenol were carried out in batch mode. The effects of operational factors, namely: 1 . type of activated sludge; 2 . concentration of activated sludge; 3 . initial concentration of phenol; and 4. addition of cosubstrate on the biodegradation efficiency and kinetics; were investigated in this study. Concentrations of phenol and dissolved oxygen (DO) as well as $\mathrm{pH}$ were monitored throughout the experiment. At the end of the biodegradation experiments, chemical oxygen demand (COD) concentration was measured on the last sample using closed reflux and titrimetric method to ascertain the attainment of mineralisation. ${ }^{18}$

\subsubsection{Types of activated sludge}

Biodegradations of phenol using unacclimated and phenol-acclimated activated sludge, respectively, were conducted in 2-1 conical flasks. A volume of 1.51 of solution containing nutrients with the same composition as the base mix mentioned previously and $50 \mathrm{mg} \mathrm{l}^{-1}$ of phenol was added into the flask. Subsequently, an amount of $200 \mathrm{mg} \mathrm{l}^{-1}$ of activated sludge was added into the solution followed by immediate aeration. Frequent sampling was carried out at regular time intervals for the determination of residual phenol concentration until the concentration was less than $1.0 \mathrm{mg}^{-1}$. The sample was filtered through filter paper Whatman No. 1 and the filtrate was analysed for the residual phenol concentration using colorimetric 4-aminoantipyrine method at the $\lambda_{\max }$ of $506 \mathrm{~nm} .{ }^{18}$

\subsubsection{Concentration of activated sludge}

The effect of concentration of activated sludge on the degradation of phenol were investigated following the procedure as described in Section 2.2.1. Unacclimated and phenol-acclimated activated sludge at different concentrations of 100 to $400 \mathrm{mg} \mathrm{l}^{-1}$, respectively, were used. 


\subsubsection{Initial concentration of phenol}

The degradation of phenol was investigated by varying the initial phenol concentration $\left(25,50,150\right.$ and $\left.250 \mathrm{mg} \mathrm{l}^{-1}\right)$ using $400 \mathrm{mg} \mathrm{l}^{-1}$ of unacclimated and phenol-acclimated activated sludge, respectively.

\subsubsection{Addition of co-substrate}

The biodegradation of $50 \mathrm{mg} \mathrm{l}^{-1}$ of phenol in the presence of sucrose as co-substrate was evaluated. Procedure as described in Section 2.2.1 was repeated with the addition of different concentration of sucrose $\left(5,10\right.$ and $\left.20 \mathrm{mg} \mathrm{l}^{-1}\right)$ and $200 \mathrm{mg} \mathrm{l}^{-1}$ of unacclimated and phenol-acclimated activated sludge, respectively.

\subsection{Kinetic Studies}

The time course data of residual phenol concentration from each of the batch experiment studies (Section 2.2) were fitted into the pseudo-first-order equation as shown in Equation 1:

$$
[\mathrm{S}]_{\mathrm{t}}=[\mathrm{S}]_{0} \exp (-\mathrm{kt})
$$

where $[\mathrm{S}]_{0}$ is the initial concentration of phenolic compounds, $[\mathrm{S}]_{\mathrm{t}}$ is the concentration of phenol at time $\mathrm{t}$ and $\mathrm{k}$ is the pseudo-first-order rate constant of phenol removal.

The values of $\mathrm{k}$ obtained were statistically analysed with two-way ANOVA test using the software Minitab version 16 and then compared in order to assess the biodegradation kinetics using unacclimated and phenol-acclimated activated sludge, respectively, under different operational conditions.

\section{RESULTS AND DISCUSSION}

\subsection{Effect of Operational Factors on Biodegradation of Phenol}

\subsubsection{Different activated sludge concentrations}

The time courses of phenol removal by unacclimated and phenol-acclimated activated sludge at various concentrations of 100 to $400 \mathrm{mg} \mathrm{l}^{-1}$ are shown in Figure 1(a) and (b), respectively. At the initial concentration of $50 \mathrm{mg}^{-1}$, phenol was completely degraded with no observable lag phase for all the cases. The time required for complete removal of phenol was found to decrease with increasing concentration of activated sludge for both unacclimated and phenol-acclimated 
activated sludge. Approximately $19 \mathrm{~h}$ was required for complete degradation of phenol at $100 \mathrm{mg} \mathrm{l}^{-1}$ of unacclimated activated sludge. The duration was reduced to $15 \mathrm{~h}, 12 \mathrm{~h}$ and $8 \mathrm{~h}$, respectively, when the activated sludge concentration was increased to 200,300 and $400 \mathrm{mg} \mathrm{l}^{-1}$. For phenol-acclimated activated sludge, approximately $9 \mathrm{~h}, 7 \mathrm{~h}, 3 \mathrm{~h}$ and $1 \mathrm{~h}$, respectively, were required for 100, 200, 300 and $400 \mathrm{mg}^{-1}$ of activated sludge. Relatively shorter biodegradation time was observed for phenol-acclimated activated sludge indicating the importance of acclimation process. Acclimation process shortened the lag phase and enhanced the degradation ability of target compound, therefore the biodegradation time became shorter. ${ }^{2,13}$ This can be supported by the findings of Lim et al. which reported the higher efficiencies of phenolic compounds removal using phenol-acclimated activated sludge compared to those of unacclimated activated sludge. ${ }^{1,2}$

\subsubsection{Different initial phenol concentrations}

Time courses of the residual phenol concentration during biodegradations by $400 \mathrm{mg} \mathrm{l}^{-1}$ of unacclimated and phenol-acclimated activated sludge at various initial phenol concentrations are shown in Figure 2(a) and (b), respectively. Complete mineralisation of phenol, which could be verified by approximately $95 \%$ COD removal, was achieved in all the cases. No lag phase was observed for all the initial phenol concentrations studied. However, for both type of activated sludge, the time required to completely remove phenol was found to increase with increasing initial phenol concentration, signifying the greater toxicity effect toward their own biodegradations attributed by the inhibited microbial growth at higher phenol concentration. ${ }^{19}$ Similar trend was reported by Saravanan et al. ${ }^{20}$ In addition, the performance of biodegradation was observed to be greatly enhanced by acclimation in spite of the low acclimation concentration of $50 \mathrm{mg}^{1-1}$. Lim et al. has shown the ability of low-strength phenol-acclimated activated sludge to completely degrade phenol at initial concentration of 7.5 times higher of which it had been acclimated. ${ }^{1}$

In this study, the phenol-acclimated activated sludge was able to remove $250 \mathrm{mg} \mathrm{l}^{-1}$ of phenol (a concentration of five times higher than the acclimation concentration) within $330 \mathrm{~min}$. However, for unacclimated activated sludge, only $50 \mathrm{mg} \mathrm{l}^{-1}$ of phenol was degraded within the same time limit. The enhancement by acclimation was found to be more pronounced at lower initial phenol concentration, in which the biodegradation time for phenol-acclimated activated sludge was found to be 9 and 7 times, respectively, shorter compared to those of unacclimated activated sludge, at the initial phenol concentration of 50 and $100 \mathrm{mg} \mathrm{l}^{-1}$. Thus, it is feasible to use low-strength phenol-acclimated activated sludge to treat wastewater containing a much higher concentration of phenol. 
(a)

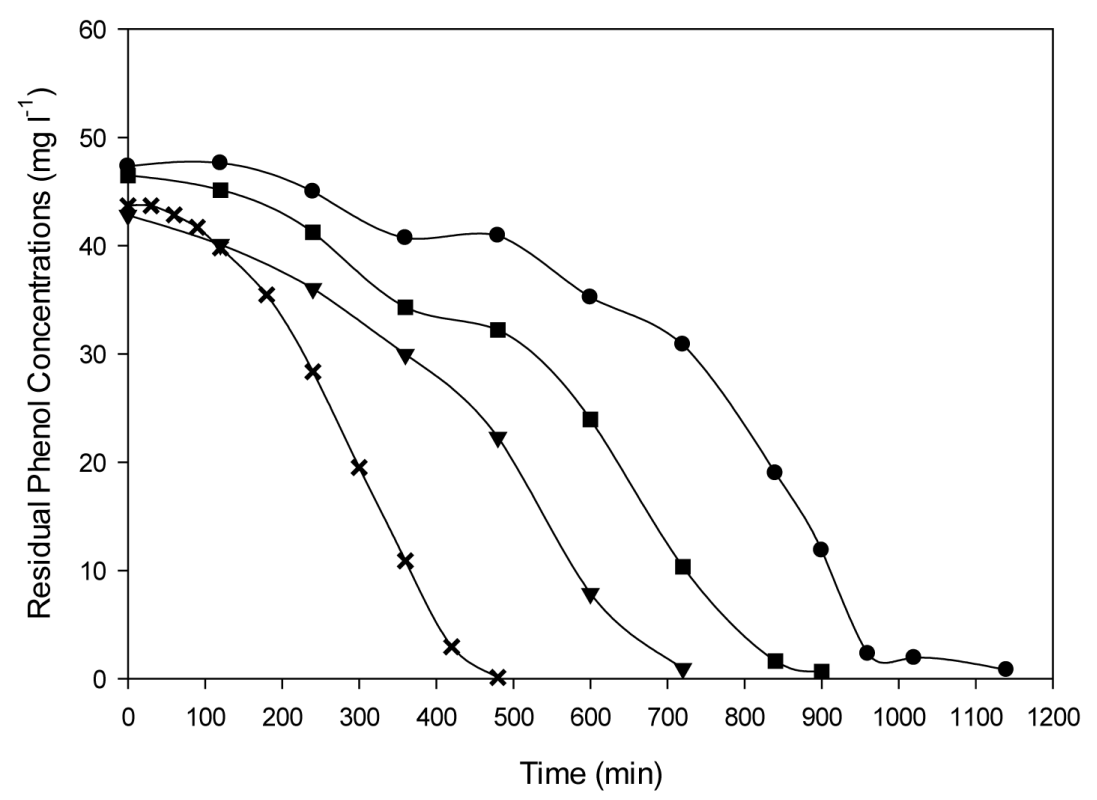

(b)

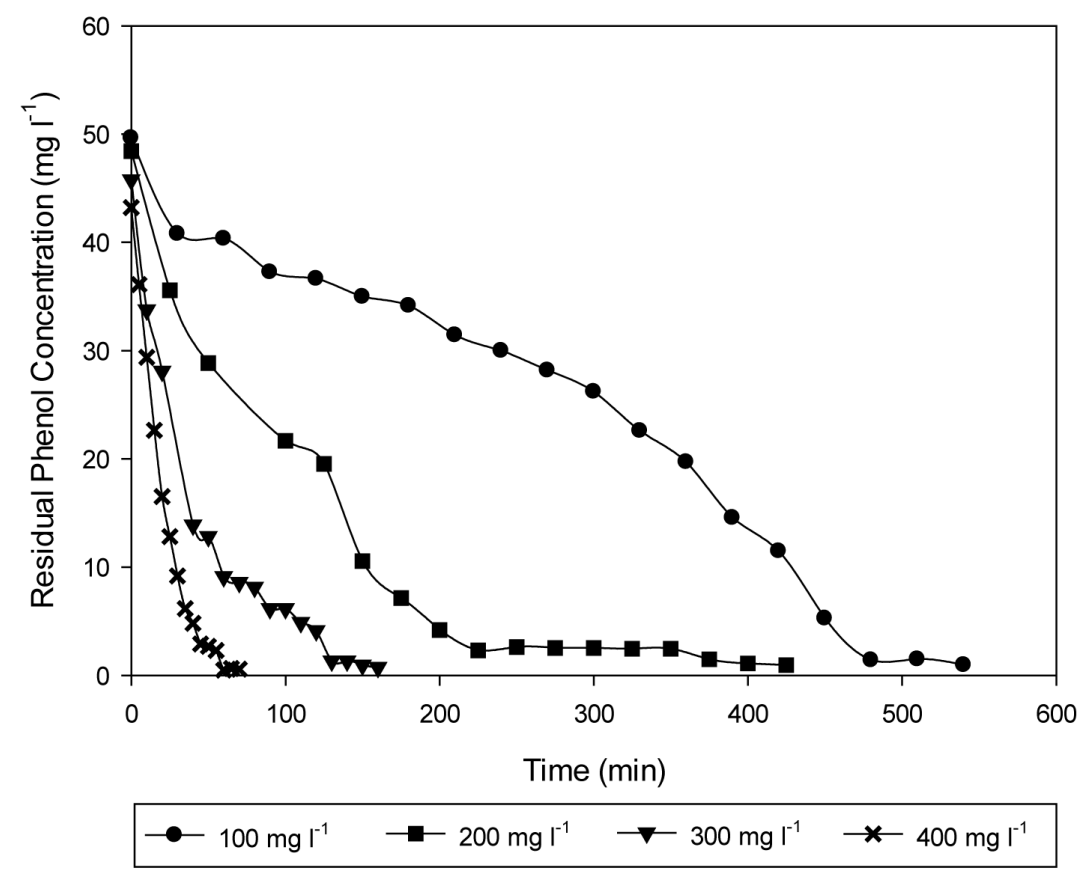

Figure 1: Time courses of the residual phenol concentration at various concentrations of (a) unacclimated and (b) phenol-acclimated activated sludge. 
(a)

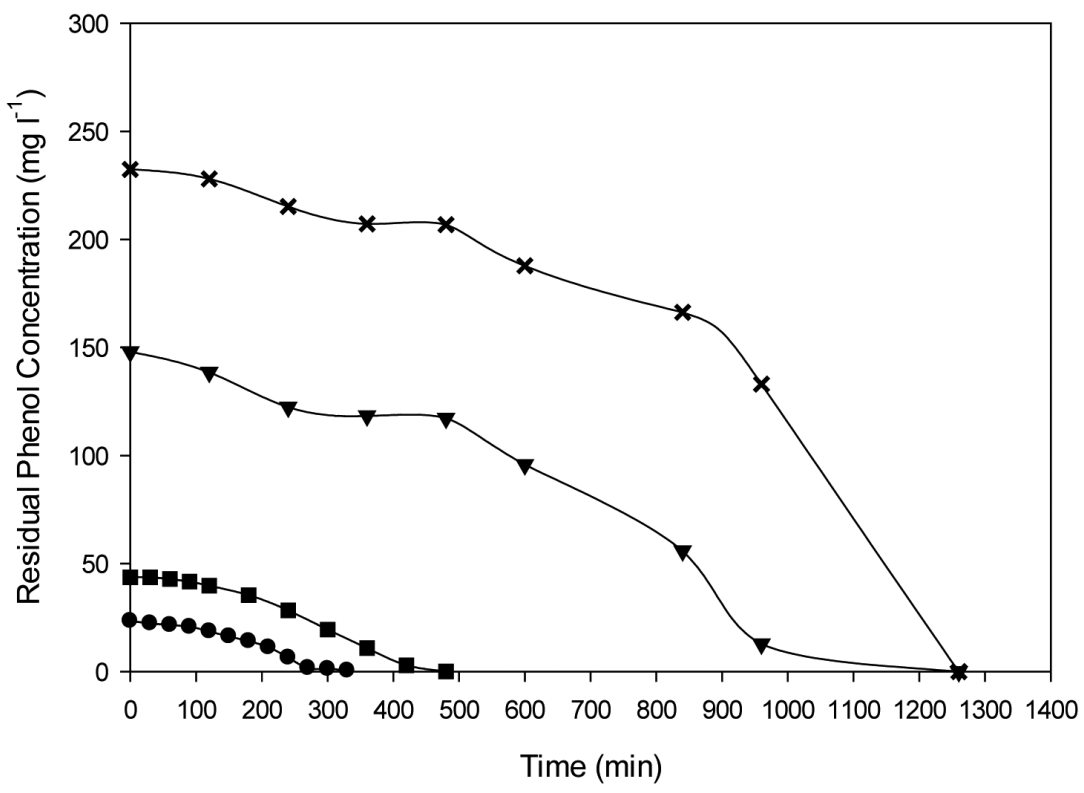

(b)

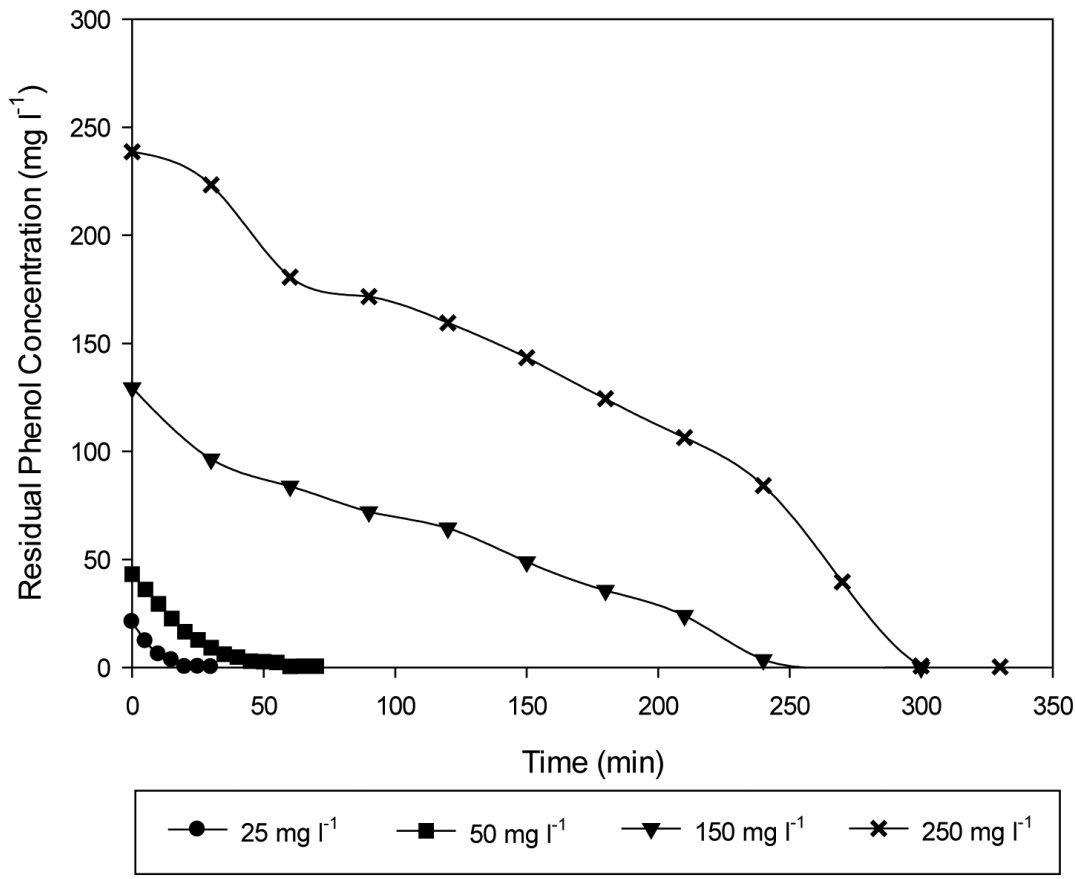

Figure 2: Time courses of the residual phenol concentration at various initial phenol concentrations for (a) unacclimated and (b) phenol-acclimated activated sludge. 


\subsubsection{Addition of co-substrate}

Time courses of residual phenol concentration during the biodegradation of phenol in the presence of various concentrations of sucrose as co-substrate using unacclimated and phenol-acclimated activated sludge, respectively, are shown in Figures 3(a) and (b). It was observed that for unacclimated activated sludge, reduction in biodegradation time was only observed for the addition of $20 \mathrm{mg} \mathrm{l}^{-1}$ of sucrose, from 900 to $720 \mathrm{~min}$. Whereas for phenol-acclimated activated sludge, more significant reduction in biodegradation time was observed, from 420 to $270 \mathrm{~min}$ in the presence of as low as $5 \mathrm{mg} \mathrm{l}^{-1}$ of sucrose. This revealed the occurrence of cometabolic biodegradation in which xenobiotic compound could be mineralised more effectively with the addition of second non-toxic substrate attributed to the decreased toxicity and growth inhibitory of xenobiotics compounds on cells. ${ }^{16}$ $\mathrm{Yu}$ and Ward reported that the degradation of pentachlorophenol (PCP) was facilitated with the addition of alternative carbon sources, such as glucose and peptone..$^{21}$ It could be plausibly explained by the role of these non-toxic carbon sources in increasing the transformation rate of xenobiotics and acting as a reducing agent for degradation of recalcitrant organic compounds as well as an inducing agent for biodegradation enzymes..$^{22,23}$

\subsection{Kinetic Study}

The kinetics of the biodegradation of phenol using unacclimated and phenolacclimated activated sludge under various operational conditions were investigated using pseudo-first-order equation (Equation 1). In this study, the values of $\mathrm{R}^{2}$ obtained ranged from 0.75 to 0.98 at different operational conditions and the values of pseudo-first-order rate constant of phenolic removal, $\mathrm{k}$, for unacclimated and phenol-acclimated activated sludge are listed in Tables 1 and 2, respectively.

The results showed that phenol-acclimated activated sludge exhibited significantly higher values of rate constant compared to unacclimated activated sludge under all the operational conditions investigated. This further substantiates the importance of acclimation on activated sludge in order to achieve more effective biodegradation of phenol, albeit the lower acclimation concentration at $50 \mathrm{mg}^{-1}$. Many previous studies have shown the importance of acclimation on activated sludge. It was manifested that phenol was degraded completely without any observable lag phase at high initial phenol concentration $\left(1050 \mathrm{mg} \mathrm{l}^{-1}\right)$ by acclimated activated sludge. In contrast, biodegradation using unacclimated activated sludge was inhibited at low concentration of phenol at only $15 \mathrm{mg} \mathrm{l}^{-1} .^{1}$ Nonetheless, it was also reported that the toxicity of $4 \mathrm{CP}$ on the activated sludge was decreased substantially and complete removal was achieved easily after acclimation. ${ }^{10}$ 
(a)

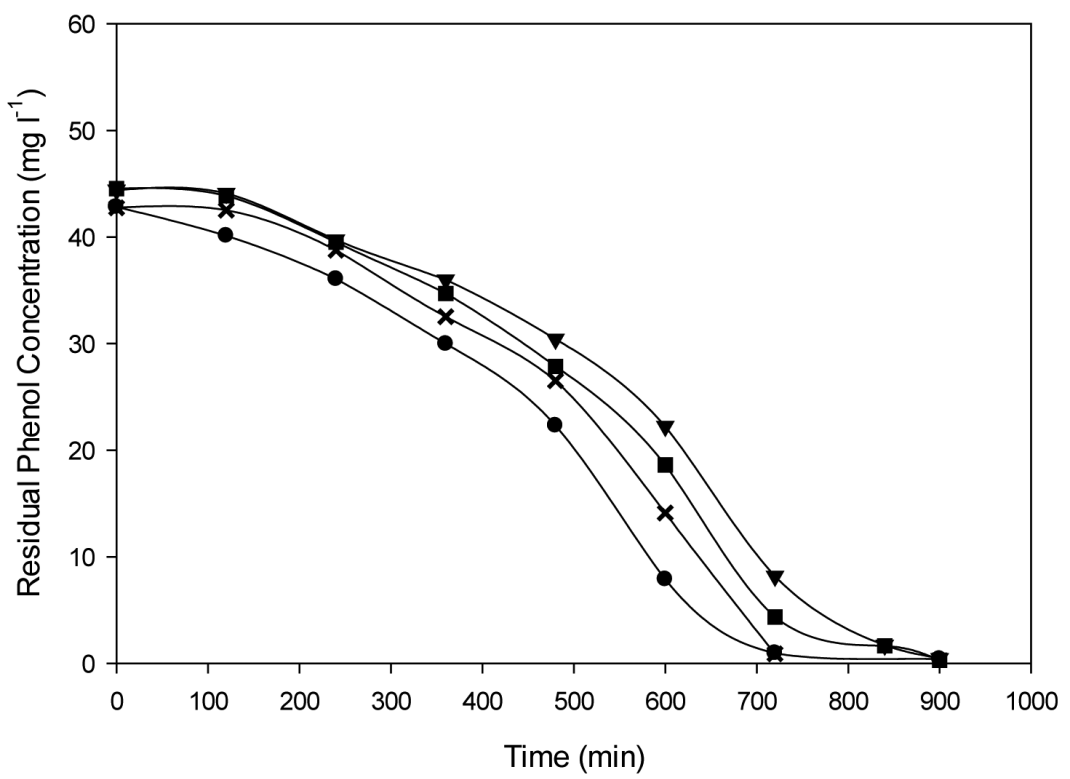

(b)

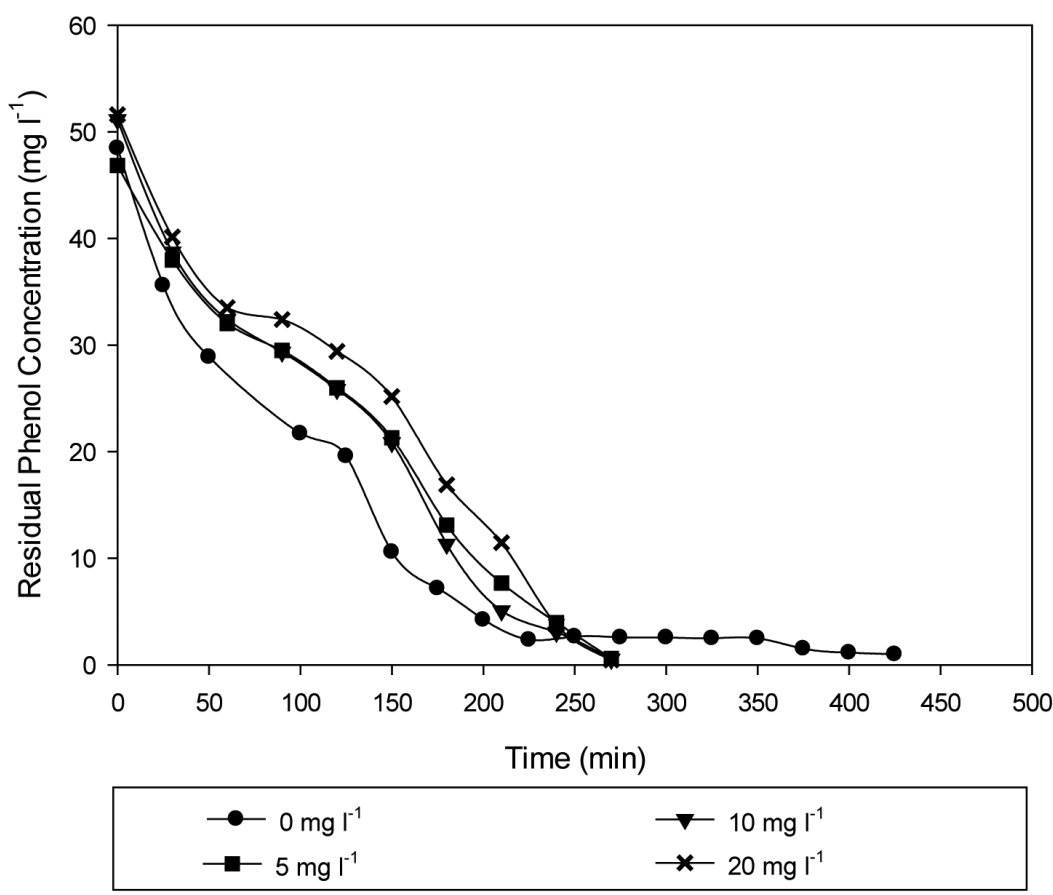

Figure 3: Time courses of the residual phenol concentration at various sucrose concentrations for (a) unacclimated and (b) phenol-acclimated activated sludge. 
Table 1: Pseudo-first-order rate constants of phenol removal, $\mathrm{k}$, under different operational conditions for unacclimated activated sludge.

\begin{tabular}{lccccc}
\hline \multicolumn{1}{c}{$\begin{array}{c}\text { Operational } \\
\text { factors }\end{array}$} & $\begin{array}{c}\text { Activated sludge } \\
\text { concentration } \\
\left(\mathrm{mg} \mathrm{l}^{-1}\right)\end{array}$ & $\begin{array}{c}\text { Initial phenol } \\
\text { concentration } \\
\left(\mathrm{mg} \mathrm{l}^{-1}\right)\end{array}$ & $\begin{array}{c}\text { Sucrose } \\
\text { concentration } \\
\left(\mathrm{mg} \mathrm{l}^{-1}\right)\end{array}$ & $\begin{array}{c}\text { Rate constant, } \\
\mathrm{k} \\
\left(\times 10^{-3} \mathrm{~min}^{-1}\right)\end{array}$ & $\mathrm{R}^{2}$ \\
\hline $\begin{array}{l}\text { Activated sludge } \\
\text { concentration }\end{array}$ & 100 & 50 & 0 & $1.00^{\mathrm{a}}$ & 0.8687 \\
& 200 & & & $1.65^{\mathrm{a}}$ & 0.8205 \\
& 300 & & & $2.25^{\mathrm{a}}$ & 0.8735 \\
& 400 & & & $5.25^{\mathrm{a}}$ & 0.8296 \\
Initial phenol & 400 & 25 & 0 & $8.15^{\mathrm{a}}$ & 0.8814 \\
concentration & 50 & & $5.25^{\mathrm{a}}$ & 08296 \\
& & 150 & & $3.90^{\mathrm{a}}$ & 0.7490 \\
& & 250 & & $0.60^{\mathrm{a}}$ & 0.8912 \\
Sucrose & & 50 & 0 & $1.65^{\mathrm{a}}$ & 0.8205 \\
concentration & 200 & & 5 & $1.30^{\mathrm{a}}$ & 0.8368 \\
& & & 10 & $1.60^{\mathrm{a}}$ & 0.7835 \\
& & & 20 & $1.35^{\mathrm{a}}$ & 0.8228 \\
\hline
\end{tabular}

Note: Mean data accompanied by different alphabet letters are significantly different (Two-way ANOVA, Tukey test, $p<0.05$ ).

Table 2: Pseudo-first-order rate constants of phenol removal, $\mathrm{k}$, under different operational conditions for phenol-acclimated activated sludge.

\begin{tabular}{lcccrc}
\hline \multicolumn{1}{c}{$\begin{array}{c}\text { Operational } \\
\text { factors }\end{array}$} & $\begin{array}{c}\text { Activated sludge } \\
\text { concentration } \\
\left(\mathrm{mg} \mathrm{l}^{-1}\right)\end{array}$ & $\begin{array}{c}\text { Initial phenol } \\
\text { concentration } \\
\left(\mathrm{mg} \mathrm{l}^{-1}\right)\end{array}$ & $\begin{array}{c}\text { Sucrose } \\
\text { concentration } \\
\left(\mathrm{mg} \mathrm{l}^{-1}\right)\end{array}$ & $\begin{array}{c}\text { Rate constant, } \\
\mathrm{k} \\
\left(\times 10^{-3} \mathrm{~min}^{-1}\right)\end{array}$ & $\mathrm{R}^{2}$ \\
\hline $\begin{array}{l}\text { Activated sludge } \\
\text { concentration }\end{array}$ & 100 & & 0 & $3.55^{\mathrm{a}}$ & 0.8259 \\
& 200 & & & $9.85^{\mathrm{a}}$ & 0.9291 \\
& 300 & & & $25.65^{\mathrm{b}}$ & 0.9424 \\
& 400 & & & $61.60^{\mathrm{c}}$ & 0.9781 \\
Initial phenol & 400 & 25 & 0 & $122.25^{\mathrm{b}}$ & 0.9201 \\
concentration & 50 & & $61.60^{\mathrm{c}}$ & 0.9781 \\
& & 150 & & $10.60^{\mathrm{a}}$ & 0.8373 \\
& & 250 & & $8.85^{\mathrm{a}}$ & 0.8517 \\
Sucrose & & 50 & 0 & $9.85^{\mathrm{b}}$ & 0.9291 \\
concentration & 200 & & 5 & $8.50^{\mathrm{b}}$ & 0.8622 \\
& & & 10 & $8.90^{\mathrm{b}}$ & 0.8766 \\
& & & 20 & $8.60^{\mathrm{b}}$ & 0.8286 \\
\hline
\end{tabular}

Note: Mean data accompanied by different alphabet letters are significantly different (Two-way ANOVA, Tukey test, $p<0.05$ ). 
For unacclimated activated sludge, the values of rate constant ranged from $1.0 \times 10^{-3}$ to $5.25 \times 10^{-3} \mathrm{~min}^{-1}$ for 100 to $400 \mathrm{mg} \mathrm{l}^{-1}$ of activated sludge, with no significant difference. In contrast, notable difference in rate constants was shown by using phenol-acclimated activated sludge. The values obtained are $3.55 \times 10^{-3}$, $9.85 \times 10^{-3}, 25.65 \times 10^{-3}$ and $61.6 \times 10^{-3} \mathrm{~min}^{-1}$ for $100,200,300$ and $400 \mathrm{mg} \mathrm{l}^{-1}$ phenol-acclimated activated sludge, respectively. A similar result was reported by Sahinkaya and Dilek, in which the degradation rate of 4CP increased with increasing concentration of biomass used. ${ }^{10}$

Furthermore, the kinetics of phenol using unacclimated activated sludge was not affected significantly by the initial phenol concentration range studied. The values of biodegradation rate constants were found to be $0.60 \times 10^{-3}$ to $8.15 \times 10^{-3} \mathrm{~min}^{-1}$ at the initial phenol concentration of 25 to $250 \mathrm{mg} \mathrm{l}^{-1}$. In contrast to unacclimated activated sludge, phenol-acclimated activated sludge exhibited remarkable reduction in the values of rate constant, from $122.25 \times 10^{-3}$ to $8.85 \times 10^{-3} \mathrm{~min}^{-1}$, when the initial phenol concentration was increased from 25 to $250 \mathrm{mg} \mathrm{l}^{-1}$. This is due to the inhibition of degradation by shock loading of high phenol concentration. In a study by Marrot et al., the inhibition effect of phenol was reported to become predominant at higher concentration and thus the low rate of substrate utilisation. ${ }^{19}$ Similar trend was shown by Lim et al. investigating the kinetics of various phenolic compounds using phenol-acclimated activated sludge. ${ }^{2}$ This phenomenon could be explained by the change in the pathway (ortho- or meta-cleavage) at different initial concentrations of phenol, resulting in the formation of distinct intermediates and thus led to slow degradation. ${ }^{24}$

As described in Section 3.3.1, phenol biodegradation time was found to decrease with the addition of sucrose (Figure 3). However, when the $\mathrm{k}$ values (Tables 1 and 2) were compared statistically, it was observed that the increase in the sucrose concentration from 0 to $20 \mathrm{mg}^{-1}$ had no significant effect on the phenol biodegradation rate constants for both the unacclimated and phenol-acclimated activated sludge. The addition of sucrose in the concentration range tested in this study was possibly too low to exert significant effect on the biodegradation rate. Tobajas et al. reported that toxicity of $4 \mathrm{CP}$ can be greatly attenuated by adding glucose as primary substrate with the concentration ranged from 25 to $250 \mathrm{mg}^{-1}$ and no lag phase was observed ${ }^{25}$ However, complete removal of $4 \mathrm{CP}$ was only achieved when the highest concentration of glucose was used. Therefore, a higher concentration of sucrose is suggested for further investigation in order to evaluate the effect of sucrose as the co-substrate on the enhancement of phenol biodegradation. 


\section{CONCLUSION}

This study was carried out to investigate the effects of operational factors, namely type of activated sludge, activated sludge concentration, initial phenol concentration and addition of sucrose on the biodegradation of phenol. In spite of the low acclimation concentration of $50 \mathrm{mg} \mathrm{l}^{-1}$, phenol-acclimated activated sludge performed more effectively during the biodegradation of phenol compared to unacclimated activated sludge. This indicates the importance of acclimation process in activated sludge. The enhancement in the biodegradation by acclimation was found to be more pronounced at high concentration of activated sludge and low initial phenol concentration. In addition, phenol biodegradation facilitated with the addition of sucrose as a co-substrate helped in decreasing the inhibitory effect on the activated sludge. For kinetic studies, the phenol-acclimated activated sludge exhibited significantly higher values of rate constant of phenol removal, $\mathrm{k}$, under all the operational conditions compared to unacclimated activated sludge. The $\mathrm{k}$ values for phenol-acclimated activated sludge increased from $3.55 \times 10^{-3}$ to $61.6 \times 10^{-3} \mathrm{~min}^{-1}$ and $8.85 \times 10^{-3}$ to $122.25 \times 10^{-3} \mathrm{~min}^{-1}$, respectively, with increasing concentrations of activated sludge from 100 to $400 \mathrm{mg} \mathrm{l}^{-1}$ and decreasing initial phenol from 250 to $25 \mathrm{mg} \mathrm{l}^{-1}$.

\section{ACKNOWLEDGEMENTS}

Financial support from Universiti Sains Malaysia (grant number 304/ PKIMIA/6313275) is gratefully acknowledged.

\section{REFERENCES}

1. Lim, J. W. et al. (2013). Response of low-strength phenol-acclimated activated sludge to shock loading of high phenol concentrations. Water $S A$, 39(5), 695-700, https://doi.org/10.4314/wsa.v39i5.14.

2. Lim, J. W., Gan, H. M. \& Seng, C. E. (2013). Bioremediation of wastewaters containing various phenolic compounds by phenol-acclimated activated sludge. Desalin. Water Treat., 51, 7018-7024, https://doi.org/10.1080/1944 3994.2013.792516.

3. Gad, N. S. \& Saad, A. S. (2008). Effect of environmental pollution by phenol on some physiological parameters of oreochromis niloticus. Glob. Vet., 2(6), 312-319.

4. Sarfaraz, S. et al. (2004). Anoxic treatment of phenolic wastewater in sequencing batch reactor. Water Res., 38, 961-971, https://doi.org/10.1016/j. watres.2003.10.039. 
5. Teh, C. Y. et al. (2016). Recent advancement of coagulation - Flocculation and its application in wastewater treatment. Ind. Eng. Chem. Res., 55, 43634389, https://doi.org/10.1021/acs.iecr.5b04703.

6. Loh, K. C. \& Tan, C. P. P. (2000). Effect of additional carbon sources on biodegradation of phenol. B. Environ. Contam. Tox., 64(6), 756-763, https://doi.org/10.1007/s0012800068.

7. Hussain, A., Kant, S. \& Kumar, V. (2015). Kinetic study for aerobic treatment of phenolic wastewater. Water Resour. Ind., 11, 81-90, https://doi. org/10.1016/j.wri.2015.05.002.

8. Lim, J. W., Tan, J. Z. \& Seng, C. E. (2013). Performance of phenolacclimated activated sludge in the presence of various phenolic compounds. Appl. Water Sci., 3, 515-525, https://doi.org/10.1007/s13201-013-0099-9.

9. Ahansazan, B. et al. (2014). Activated sludge process overview. IJESD, 5(1), 1-5.

10. Sahinkaya, E. \& Dilek, F. B. (2005). Biodegradation of 4-chlorophenol by acclimated and unacclimated activated sludge - Evaluation of biokinetic coefficients. Environ. Res., 99, 243-252, https://doi.org/10.1016/j.envres. 2004.11.005.

11. Kim, J. H. et al. (2002). Biodegradation of phenol and chlorophenols with defined mixed culture in shake-flasks and a packed bed reactor. Process Biochem., 37(12), 1367-1373, https://doi.org/10.1016/S00329592(02)00007-9.

12. Ng, S. L., Seng, C. E. \& Lim, P. E. (2009). Quantification of bioregeneration of activated carbon and activated rice husk loaded with phenolic compounds. Chemosph., 75, 1392-1400, https://doi.org/10.1016/j. chemosphere.2009.02.049.

13. Vázquez-Rodríguez, G., Youssef, C. B. \& Waissman-Vilanova, J. (2006). Two-step modeling of the biodegradation of phenol by an acclimated activated sludge. Chem. Eng. J., 117, 245-252, https://doi.org/10.1016/j. cej.2005.11.015.

14. Janeczko, A. \& Oleszkiewicz, J. A. (2015). Response of acclimated and unacclimated activated sludge to 2-nitrophenol response of acclimated and un-acclimated activated sludge to 2-nitrophenol. Environ. Technol., 14(4), 351-358, https://doi.org/10.1080/09593339309385299.

15. Alvarez-Cohen, L. \& Mccarty, P. L. (1991). A cometabolic biotransformation model for halogenated aliphatic-compounds exhibiting product toxicity. Environ. Sci. Technol., 25(8), 1381-1387, https://doi.org/10.1021/ es00020a003. 
16. Wang, S. J. \& Loh, K. C. (2000). New cell growth pattern on mixed substrates and substrate utilization in cometabolic transformation of 4-chlorophenol. Water Res., 34(15), 3786-3794, https://doi.org/10.1016/ S0043-1354(00)00144-5.

17. Arutchelvan, V. et al. (2006). Kinetics of high strength phenol degradation using Bacillus brevis. J. Hazard. Mater., 129, 216-222, https://doi.org/ 10.1016/j.jhazmat.2005.08.040.

18. Rice, E. W. et al. (2013). APHA standard method for the examination of water and wastewater, 22nd ed. New York: American Public Health Association.

19. Marrot, B. et al. (2006). Biodegradation of high phenol concentration by activated sludge in an immersed membrane bioreactor. Biochem. Eng. J., 30, 174-183, https://doi.org/10.1016/j.bej.2006.03.006.

20. Saravanan, P., Pakshirajan, K. \& Saha, P. (2008). Growth kinetics of an indigenous mixed microbial consortium during phenol degradation in a batch reactor. Biores. Technol., 99, 205-209, https://doi.org/10.1016/j. biortech.2006.11.045.

21. Yu, J. \& Ward, O. P. (1994). Studies on factors influencing the biodegradation of pentachlorophenol by a mixed bacterial culture. Int. Biodeter. Biodegr., 33(2), 209-221, https://doi.org/10.1016/0964-8305(94)90061-2.

22. Perkins, P. S. et al. (1994). Effects of electron donors and inhibitors on reductive dechlorination of 2,4,6-trichlorophenol. Water Res., 28(10), 21012107, https://doi.org/10.1016/0043-1354(94)90020-5.

23. Loh, K. C. \& Wang, S. J. (1997). Enhancement of biodegradation of phenol and a nongrowth substrate 4-chlorophenol by medium augmentation with conventional carbon sources. Biodegr., 8, 329-338, https://doi.org/ 10.1023/A: 1008267607634 .

24. Loh, K. C. \& Chua, S. S. (2002). Ortho pathway of benzoate degradation in Pseudomonas putida: Induction of meta pathway at high substrate concentrations. Enzyme Microb. Technol., 30(5), 620-626, https://doi.org/ 10.1016/S0141-0229(02)00016-9.

25. Tobajas, M. et al. (2012). Enhancement of cometabolic biodegradation of 4-chlorophenol induced with phenol and glucose as carbon sources by Comamonas testosteroni. J. Environ. Manage., 95, 116-121, https://doi.org/ 10.1016/j.jenvman.2010.09.030. 